\title{
$\cong$ Acerca del Estado regional y la nueva constitución. Presente y por-venir ${ }^{1}$
}

\author{
About the regional State and \\ the new Constitution. \\ Present and future
}

\author{
FRANCISCO ZÚÑIGA URBINA \\ Profesor titular del Departamento de Derecho \\ Público. Universidad de Chile. \\ fzuniga@zcabogados.cl
}

DOI: 10.2436/20.8080.01.45

Fecha de recepción: 20/11/2020

Fecha de aceptación:05/12/2020

\section{Resumen}

En el presente artículo se analiza la reforma constitucional impulsada por el segundo gobierno de Michelle Bachelet (2014-2018) sobre Estado regional y los nuevos órganos: gobernador regional, delegación presidencial regional, materializada en la Ley de reforma constitucional No 20.990, que busca obtener un país más descentralizado y desconcentrado institucionalmente, trasladando las funciones propias del intendente regional a estas nuevas figuras. Además, se aborda cómo se proyectaría la distribución territorial del poder en el debate de contenidos de la nueva Constitución, en la Convención Constitucional elegida el 11 de abril de 2021.

Palabras clave

Estado regional; gobierno regional; descentralización; desconcentración.

\begin{abstract}
This article analyzes the constitutional reform promoted by the second government of Michelle Bachelet (2014-2018) on the regional state and the new bodies: regional governor, regional presidential delegation, materialized in Constitutional Reform Law No. 20,990, which seeks to obtain a more decentralized and institutionally deconcentrated country, transferring the functions of the regional mayor to these new figures. In addition, it addresses how the territorial distribution of power would be projected in the debate on the contents of the new Constitution, in the Constitutional Convention elected on April 11, 2021.
\end{abstract}

\section{Keywords}

Regional state; regional government; decentralization; deconcentration.

1 Ponencia efectuada en seminario del H. Senado de la República de Chile, inédita y actualizada; de fecha 12 de noviembre de 2020. 


\section{Presentación - II. Camino al Estado regional. - III. El desafío de un Estado regional. - IV.Conclusiones. Bibliografía.}

\section{Presentación}

En los últimos años se ha incrementado el debate acerca de la necesidad de un Estado regional y de una desconcentración-descentralización efectiva en nuestro país, en particular con el programa del segundo gobierno de Bachelet que ha impulsado diversas iniciativas que van orientadas a distribuir el poder político-estatal en el territorio; de la mano de una fuerte impronta republicano-democrática.

No es la primera vez que nos terciamos frente al modelo de Estado heredado de la consolidación del Estado nacional: el Estado unitario, firmemente anclado en un modelo de Estado propio de la revolución político-burguesa: el Estado jacobino-napoleónico; que retoma la centralización de los borbones en Francia y España y que se proyecta en el derecho público indiano en América Latina como bien destaca Véliz (1984: 348).

El Estado unitario y la centralización político-administrativa cuenta a su haber con el peso del pasado. El peso del pasado se proyecta en la teoría constitucional en la "Constitución histórica", como advertía Marx (1842-1843/1983) en sus escritos juveniles para bendecir o santificar el látigo, en la dialéctica amo-siervo criticando a Hugo y a Savigny; y también se proyecta en la exquisitez dogmática de la "Constitución material" de Mortati (1940/2001) que justifica el statu quo. La premisa básica del "historicismo" es negarse al cambio o condenarlo de antemano como un cambio gatopardiano a lo Lampedusa: "Si queremos que todo siga como está, es necesario que todo cambie". El que la regionalización como proceso hubiere comenzado bajo el régimen autoritario (1975) no es contradictorio si se define correctamente su horizonte geopolítico, económico e institucional centrado en la desconcentración de la Administración con resabios funcionalistas de representación corporativista en comunas y regiones (CODECOS y COREDES).

Luego, un nuevo reparto territorial del poder político estatal (Administración y Gobierno) desafía al pasado. En efecto, con la intención de traspasar el poder desde el Estado central (Administración) a las regiones, el programa gubernamental señaló que la nueva Constitución "romperá con el centralismo del Estado chileno. Se establecerán gobiernos regionales que, liderados por jefes ejecutivos elegidos por votación directa, dispondrán de autonomía, facultades y recursos suficientes para constituirse en verdaderos ejes del desarrollo territorial" 2 .

Es conocido por este selecto público aquí presente que nuestro país enfrenta graves desigualdades-asimetrías como país y en el ámbito territorial, que trae como consecuencias, entre otros, problemas de acceso a una mayor igualdad, un desarrollo económico, social y cultural inarmónico y falta de democratización de las decisiones que son determinantes para la población de cada región.

2 Chile de todos. Programa de Gobierno Michelle Bachelet 2014-2018, 34. 
En este sentido, el programa del pasado gobierno de Bachelet plantea que con el fin de promover el fortalecimiento de la regionalización del país, del desarrollo equitativo entre las regiones y democratizar las instituciones era necesario extender la elección directa que ya existe en el caso de alcaldes, concejales, y consejeros regionales a la máxima autoridad regional ${ }^{3}$, lo que deberá considerarse en la nueva Constitución, junto con la necesaria autonomía administrativa del gobierno regional, especialmente en las materias relacionadas con el desarrollo y planificación del territorio. Luego la reforma constitucional promulgada mediante la Ley $\mathrm{N}^{\circ} 20.990$ de 2017, es un adelantamiento parcial de contenidos de una nueva Constitución y que es fruto del trabajo de la Comisión de Descentralización creada para proponer mecanismos e instituciones para avanzar cualitativamente en descentralización y más democracia; Comisión que concluyó exitosamente su tarea y materializó sus acuerdos en un macizo informe ${ }^{4}$.

\section{Camino al Estado regional}

Los avances en el campo de la desconcentración-descentralización institucional y del desarrollo regional han sido graduales y tímidos. Es así que en el año 2009 se dio un paso significativo en el fortalecimiento de las regiones con la reforma constitucional que permitió disponer de la elección de consejeros regionales por votación directa del cuerpo electoral regional. Al mismo tiempo se avanzó tímidamente en el traspaso de algunas de las funciones propias de los ministerios a gobiernos regionales. Además, entre otros proyectos legislativos de interés fue promulgada este año la Ley $\mathrm{N}^{\circ} 20.757$, que regula el estatuto aplicable a los presidentes de consejos regionales y fue incorporado el "Fondo de Convergencia" en la Ley de Presupuestos del Sector Público desde el año 2015.

La reforma constitucional de 2017 sobre elección de gobernadores regionales entronca con la efímera experiencia federal en los albores del Estado nacional, en que la ley de 12 de octubre de 1826 estableció la elección directa mediante sufragio ampliado de intendentes por provincia; idea central del proyecto de Constitución federal y del ideario defendido por Infante desde "El Valdiviano Federal" y complementario de la ley que estableció "Asambleas Provinciales" con diputados elegidos popularmente en razón de uno por cada curato, órganos revestidos de potestad legislativa (Heise González, 1954: 46-48).

Sin embargo, el modelo de Estado unitario centralista comienza a implantarse con la Constitución liberal de 1828, la que hace un modesto reconocimiento a los sectores federalistas al conservar las "Asambleas Provinciales" y las provincias históricas (Coquimbo, Aconcagua, Santiago, Colchagua, Maule, Concepción, Valdivia y Chiloé) (Heise González, 1960).

Asimismo, entroncado con el pasado y en el marco del fortalecimiento de la regionalización del país, a principios de este 2017 se publicó el texto definitivo de la Ley N²0.990 de reforma constitucional que dispone la elección popular del órgano ejecutivo del gobierno regional, el cual se esperaba que tuviera efectos para la elección directa de gobernadores regionales conjuntamente con las elecciones políticas generales del año 2017, para así asumir junto con el nuevo

3 Chile de todos. Programa de Gobierno Michelle Bachelet 2014-2018, 114.

4 Comisión Asesora Presidencial en Descentralización y Desarrollo Regional. Propuesta de política de Estado y Agenda para la descentralización y desarrollo territorial de Chile, Valparaíso, 2014. 
mandato presidencial en marzo del 2018; siempre que fuera promulgada la ley orgánica constitucional que determine la forma y el modo en que el Presidente de la República podrá transferir a uno o más gobiernos regionales, en carácter temporal o definitivo, una o más de sus competencias. Ello no ocurrió y recién ahora el Congreso Nacional ha despachado los proyectos de ley y de reforma constitucional que permitirían la elección general administrativa simultánea el 11 de abril de $2021^{5}$.

La Ley N²0.990 de reforma constitucional que dispone la elección popular del órgano ejecutivo del gobierno regional fue iniciada por la Presidenta de la República Michelle Bachelet y está basado en la configuración del Estado como una república democrática, la cual, según el mensaje, requiere de una mayor descentralización, siendo necesaria "una política consistente y multisectorial en materia de desarrollo de las regiones, que considere la especificidad de cada una, siendo necesario que las soluciones a los diversos problemas que existen en las quince regiones del país sean definidas con creciente participación de los niveles subnacionales"6.

Por su parte, la cuestión de la función ejecutiva regional no se limita a la aspiración histórica de la elección popular de la máxima autoridad en el territorio, sino que es un poco más compleja. No se pone en duda que los intendentes (futuros gobernadores regionales) deban ser elegidos por el pueblo o cuerpo electoral de la región en forma directa mediante sufragio universal; pero resulta también esencial separar las funciones que actualmente ejercen.

Esto, porque la utilización que la Constitución vigente hace del concepto de "gobierno regional" resulta contradictoria o, al menos, carente de contenido específico, pues actualmente los gobiernos regionales tienen por función casi principal administrar políticas sectoriales definidas por la Administración central. Es un término que se remonta a la reforma constitucional de 1991; que instituye "gobiernos regionales" que no gobiernan, sino que tienen a su cargo la administración superior de la región. De esta forma, actualmente no existe una distinción adecuada entre las funciones de gobierno y administración, por cuanto se asigna a la misma autoridad (el Intendente) tanto la representación en la región del Presidente de la República como la titularidad del órgano ejecutivo del Gobierno Regional, pese a la relativamente reciente aparición del Presidente del Consejo Regional. El intendente hoy es todavía un "órgano bifronte" (Luksic, 1992), titular de potestades diferenciadas y con una relación dual, un personaje propio de R. L. Stevenson (Jekyll y Hyde).

Así, actualmente es la figura del Intendente Regional quien ejerce las tareas como poder ejecutivo de gobierno en la región respecto de la administración y como representante del Presidente de la República. Al respecto, el mensaje señala que "en cuanto representante del Presidente, resulta lógico que sea nombrado por él. Sin embargo, hoy en día, cuando los ciudadanos eligen alcaldes, concejales, parlamentarios y consejeros regionales, y en circunstancias que el Intendente dirige un cuerpo constituido por autoridades electas democráticamente, su carácter designado resulta anómalo"7, es así que se considera imprescindible que la máxima autoridad ejecutiva en la región sea elegida por la ciudadanía mediante votación directa.

5 Boletín N¹1200-06, que Regula la elección de gobernadores regionales y realiza adecuaciones a diversos cuerpos legales, proyecto que se encuentra actualmente en el TC para control obligatorio y preventivo de constitucionalidad, Rol N 4214-17

6 Mensaje de S.E. Presidenta de la República con el que inicia proyecto de reforma constitucional, que dispone la elección popular del órgano ejecutivo del gobierno regional, 3.

7 Ibidem. 
A través de la Ley No 20.990 se modifica el artículo 111 de la Constitución y se dispone la creación de la autoridad de "gobernador regional" que sustituye al Intendente y que será elegido por sufragio universal, en votación directa, por simple mayoría de los votos válidamente emitidos (equivalente al menos al $40 \%$ de los votos válidamente emitidos), durando cuatro años en su cargo, siendo posible la reelección por una sola vez.

Artículo 125 bis. Para determinar el límite a la reelección que se aplica a los gobernadores regionales, consejeros regionales, alcaldes y concejales, se considerará que han ejercido su cargo durante un período cuando hayan cumplido más de la mitad de su mandato. ${ }^{8}$

Dentro de sus funciones se contempla aquellas que se relacionen con la representación del Poder Ejecutivo en la región respectiva, presidiendo el consejo regional y otras tareas que se le asignen en coordinación con los servicios públicos que operen en la región y que dependan o se relacionen con el gobierno regional.

El texto de reforma que fue aprobado en un principio por la Cámara de Diputados el 8 de noviembre de 2016, contenía que la elección del gobernador regional sería en conjunto con las de consejeros regionales, así como también el procedimiento en caso de que exista empate entre candidatos, contemplando además elecciones en caso de vacancia cuando faltare un año o más para la próxima elección. El texto aprobado definitivamente se hizo cargo de esta particularidad. El nuevo texto incluye además la facultad del consejo regional de fiscalizar los actos del gobierno regional, pudiendo entregar observaciones que se transmitirán por escrito al gobernador regional, con el acuerdo de un tercio de los consejeros, o de requerir individualmente al gobernador regional la información necesaria, reforzando así la correspondiente función de fiscalización del consejo regional del artículo 36 letra g) de la Ley N019.175.

El texto que fue aprobado y promulgado por la Ley No20.990 establece la modificación del artículo 111 de la Constitución Política de la República, quedando el definitivo como sigue:

Artículo 111.- La administración superior de cada región reside en un gobierno regional, que tendrá por objeto el desarrollo social, cultural y económico de la región.

El gobierno regional estará constituido por un gobernador regional y el consejo regional. Para el ejercicio de sus funciones, el gobierno regional gozará de personalidad jurídica de derecho público y tendrá patrimonio propio.

El gobernador regional será el órgano ejecutivo del gobierno regional, correspondiéndole presidir el consejo y ejercer las funciones y atribuciones que la ley orgánica constitucional determine, en coordinación con los demás órganos y servicios públicos creados para el cumplimiento de la función administrativa. Asimismo, le corresponderá la coordinación, supervigilancia o fiscalización de los servicios públicos que dependan o se relacionen con el gobierno regional.

El gobernador regional será elegido por sufragio universal en votación directa. Será electo el candidato a gobernador regional que obtuviere la mayoría de los sufragios válidamente emitidos y siempre que dicha mayoría sea equivalente, al menos, al cuarenta por ciento de los votos válidamente

8 Artículo incorporado mediante la ley de reforma constitucional N²1.238, de 2020. 
emitidos, en conformidad a lo que disponga la ley orgánica constitucional respectiva. Durará en el ejercicio de sus funciones por el término de cuatro años, pudiendo ser reelegido consecutivamente sólo para el período siguiente. Si a la elección del gobernador regional se presentaren más de dos candidatos y ninguno de ellos obtuviere al menos cuarenta por ciento de los sufragios válidamente emitidos, se procederá a una segunda votación que se circunscribirá a los candidatos que hayan obtenido las dos más altas mayorías relativas y en ella resultará electo aquel de los candidatos que obtenga el mayor número de sufragios. Esta nueva votación se verificará en la forma que determine la ley.

Para los efectos de lo dispuesto en los dos incisos precedentes, los votos en blanco y los nulos se considerarán como no emitidos.

La ley orgánica constitucional respectiva establecerá las causales de inhabilidad, incompatibilidad, subrogación, cesación y vacancia del cargo de gobernador regional, sin perjuicio de lo dispuesto en los artículos 124 y 125.

Con todo, el pasado es el pasado, y se hace sentir (preservando la unidad política o gubernativa del Estado); previéndose en la reforma constitucional una suerte de "prefecto" del modelo francés (delegado presidencial regional) (Chapman, 1959). En efecto, la nueva norma contempla la existencia de una delegación presidencial regional, a cargo de un delegado, que es nombrado directamente por el Presidente de la República, conservando la representación natural e inmediata que tiene hoy el Intendente Regional en el territorio y sus funciones, entre otras, la función de gobierno interior y la coordinación, supervigilancia y fiscalización de los servicios creados para el cumplimiento de la función administrativa en la región o que dependan o se relacionen con el Presidente de la República a través de un Ministerio.

Si bien en un principio el proyecto aprobado por la Cámara de Diputados el año 2016 contemplaba dicha autoridad como "secretario presidencial regional", el texto definitivo que fue promulgado como ley de la República se indica como la figura de "delegado presidencial regional".

La reforma constitucional contempla así un nuevo artículo 115 bis:

Artículo 115 bis.- En cada región existirá una delegación presidencial regional, a cargo de un delegado presidencial regional, el que ejercerá las funciones y atribuciones del Presidente de la República en la región, en conformidad a la ley. El delegado presidencial regional será el representante natural e inmediato, en el territorio de su jurisdicción, del Presidente de la República y será nombrado y removido libremente por él. El delegado presidencial regional ejercerá sus funciones con arreglo a las leyes y a las órdenes e instrucciones del Presidente de la República.

Al delegado presidencial regional le corresponderá la coordinación, supervigilancia o fiscalización de los servicios públicos creados por ley para el cumplimiento de las funciones administrativas que operen en la región que dependan o se relacionen con el Presidente de la República a través de un Ministerio.

Además del delegado regional presidencial, se contempla la autoridad del delegado provincial presidencial, nombrado por el Presidente de la República, para cada provincia, modificándose el inciso primero del artículo 116 en los siguientes términos:

Artículo 116.- En cada provincia existirá una delegación presidencial provincial, que será un órgano territorialmente desconcentrado del delegado presidencial 
regional, y estará a cargo de un delegado presidencial provincial, quien será nombrado y removido libremente por el Presidente de la República. En la provincia asiento de la capital regional, el delegado presidencial regional ejercerá las funciones y atribuciones del delegado presidencial provincial.

Las enmiendas introducidas y con las cuales fue aprobado el proyecto por la Cámara de Diputados corrigieron algunas falencias del texto original como la previsión de casos de empate y vacancia, así como también refuerza la función fiscalizadora del Consejo Regional respecto de los gobernadores y su responsabilidad en el ejercicio de sus funciones. A pesar de ello, el nuevo texto del artículo 113 aparece algo confuso, siendo recomendable que se dividan aquellas cuestiones relativas a la organización del Consejo de las relacionadas con sus funciones.

De esta forma, podemos señalar que en general las funciones y atribuciones de los gobernadores regionales serán aquellas que la Constitución y las leyes otorgan expresamente al intendente como órgano ejecutivo regional, mientras que las restantes funciones y atribuciones que la Constitución y las leyes otorgan al intendente se entenderán que corresponden al delegado presidencial regional.

Más específicamente, y en relación con dichas funciones y atribuciones, es fundamental señalar que con fecha 23 de Enero del 2018, fue declarado conforme a la Constitución, por parte del Tribunal Constitucional, el proyecto de ley relativo al fortalecimiento de la regionalización (Ley $\left.N^{\circ} 21.074\right)$, luego de múltiples controversias en torno, principalmente, a atribuciones de las nuevas autoridades operantes en cada región y la transferencia de competencias que deben derivarse a los gobiernos regionales desde entidades, servicios u organizaciones del Gobierno central. Respecto al primer tópico, dentro de las principales atribuciones y competencias de los gobiernos regionales se encuentran diseñar, elaborar, aprobar y aplicar políticas, planes, programas y proyectos de desarrollo de la región dentro del ámbito de sus competencias; orientar el desarrollo territorial de la región en coordinación con servicios públicos y municipalidades; elaborar y aprobar su proyecto de presupuesto; administrar fondos y programas de aplicación regional, entre otros, siendo probablemente una de las más relevantes elaborar y aprobar el plan regional de ordenamiento territorial en coherencia con la estrategia regional de desarrollo y la política nacional de ordenamiento territorial. Así, se establece en el mismo proyecto de ley que el plan regional de ordenamiento territorial es "un instrumento que orienta la utilización del territorio de la región para lograr su desarrollo sustentable a través de lineamientos estratégicos y una macro zonificación de dicho territorio". En relación ahora con el segundo tópico, es decir con las normas sobre transferencia de competencias desde el Gobierno Central, se detalla en el proyecto de ley que "el Presidente de la República transferirá, a uno o más gobiernos regionales, en forma temporal o definitiva, una o más competencias de los ministerios y de los servicios públicos a que se refiere el artículo 28 de la ley $N^{\circ} 18.575 "$ ", debiendo estar estas competencias necesariamente enmarcadas en el ordenamiento territorial, fomento productivo y desarrollo social y cultural. En el marco de la discusión del proyecto, se puso énfasis en el hecho de que se privilegiará el traspaso de competencias que tengan clara aplicación regional, es decir, aquellas cuya aplicación signifique una mejor calidad y oportunidad en la toma de decisiones y una mejor adecuación de la política nacional en el territorio. Es menester mencionar, además, que las competencias serán ejercidas por el gobierno regional a través de sus divisiones, y de conformidad a las políticas públicas nacionales, permitiendo el mismo proyecto de ley la creación de nuevos servicios públicos que dependerán o se relacionarán con el gobierno 
regional de acuerdo a "las capacidades que cada gobierno regional ha generado y las competencias que cada uno ha adquirido".

Por otro lado, la Ley $N^{\circ} 21.073$ que regula la elección de gobernadores regionales y realiza adecuaciones a diversos cuerpos legales (Boletín $\left.N^{\circ} 11200-06\right)^{9}$, busca viabilizar la reforma constitucional de diciembre de 2017, en las elecciones administrativas del 11 de abril de 2021, previstas originalmente el año 2020 y postergadas a 2021 por la pandemia del COVID-19, mediante Ley $N^{\circ} 21.221$ de reforma constitucional, que estableció un nuevo "itinerario electoral".

Con todo, y aún en consideración de dichos avances legislativos, es menester hacer un balance provisional. Un Estado con regiones con mayor autonomía se trata de una auténtica innovación respecto de los equilibrios políticos, sociales y económicos del territorio nacional y el ejercicio efectivo de las regiones de un gobierno más cercano con la comunidad y los ciudadanos. Sin embargo, el reconocimiento de una muy débil autonomía política a través de la elección popular del gobernador regional y el consecuente traspaso de poder requieren, además, del fortalecimiento de los mecanismos de participación ciudadana en la región como espacio más cercano y del control ciudadano al actuar como su representante. Todo ello sin perjuicio del sistema de control social del poder político en la región y del control jurídico y de legalidad, propios de un moderno Estado de Derecho

Además, sea por la vía de la transferencia de funciones y atribuciones, o mediante el traspaso de servicios públicos a los gobiernos regionales, éstos verán incrementado de forma sustantiva su ámbito de acción. Por ello, resulta natural dotarlos de la estructura institucional y económica necesaria para poder cumplir a cabalidad su tarea de satisfacer las necesidades de la comunidad regional.

\section{El desafío de un Estado regional}

En el marco de una nueva Constitución, la Convención Constitucional, que resulte de las elecciones de convencionales constituyentes de 11 de abril de 2021, está desafiada a cortar la cadena que une la distribución territorial del país con el modelo de Estado unitario centralista consolidado en 1833. Es por ello preciso apuntar una serie de consideraciones, ya sostenidas en otro lugar (Zúñiga Urbina y Peroti Díaz, 2020: 27-30) ${ }^{10}$, con carácter de balance y prospectiva crítica:

Desde la fundación del Estado chileno ha sido un Estado unitario con fuertes elementos de centralización política herencia, del pasado colonial y de la monarquía borbónica y el molde afrancesado del Estado jacobino-napoleónico con el breve interludio del ensayo federal. De esta suerte, se impone hoy la asunción de una nueva forma jurídica del Estado que retome la tradición regional, provincial y municipalista y dé un salto cuantitativo y cualitativo en la distribución territorial del poder político fortaleciendo la regionalización y evitando la provincialización regresiva de este proceso.

El régimen de "Gobierno y Administración Regional" ha avanzado significativamente desde la reforma constitucional No 19.097, de 12 de noviembre de 1991 que instaura la creación de los gobiernos regionales, integrado por un órgano ejecutivo (el Intendente Regional) y un órgano colegiado (el consejo

9 El proyecto se encuentra actualmente en el TC para control obligatorio y preventivo de constitucionalidad, Rol N 4214-17

10 En este punto en particular el aporte corresponde al profesor Rodrigo Pérez Lisicic. 
regional). Existen tres ideas a destacar de esta histórica reforma a la Constitución autoritaria de 1980. La primera de ellas, la reforma al esquema de "Gobierno y Administración Interior del Estado" chileno fue una reforma que pasó inadvertida ante la opinión pública y que, en consecuencia, no tuvo el reconocimiento que se merecía tras haber superado 157 años de centralismo político y jurídico desde la Constitución de 1833, la que había eliminado las asambleas provinciales contempladas por la Constitución de 1828. La Constitución de 1925, que las había contemplado, el Presidente de la República optó mediante decreto con fuerza de ley asignar las atribuciones de las asambleas provinciales dentro de las potestades presidenciales, circunstancias que se mantuvo hasta el 11 de septiembre de 1973. La segunda idea, es la creación de una doble función del Intendente Regional, vale decir, desde el año 1991, el Intendente Regional, es el representante natural e inmediato del Presidente de la República en el territorio de su jurisdicción y ejecuta, por tanto, las competencia propias de gobierno interior; por otra parte, el Intendente es órgano ejecutivo del Gobierno Regional y lo preside desarrollando las funciones propias de administración regional. Este carácter "bicéfalo" de las competencias del Intendente se mantendrá hasta el inicio de la entrada en vigor de la reforma constitucional que contempla la figura del gobernador regional, de naturaleza electiva por sufragio universal. $Y$ la tercera idea, se refiere al nuevo ciclo de reforma al modelo de "Gobierno y Administración Regional" del Estado instaurado por un conjunto de reformas constitucionales que tienden a mejorar la representatividad de las autoridades regionales (consejeros regionales y gobernador regional) y fortalecer las regiones del territorio nacional.

Entre las reformas constitucionales destacan:

a) La Ley No 20.390, que establece la elegibilidad de los consejeros regionales por sufragio universal.

b) La Ley No 20.990, que establece la elección popular del órgano ejecutivo del Gobierno Regional (gobernador regional).

c) La Ley $N^{\circ} 20.346$, que establece normas sobre asociacionismo municipal.

d) La Ley No 20.573, por la cual se crean territorios especiales de Isla de Pascua y del Archipiélago Juan Fernández.

e) La Ley No 20.644, que crea una Disposición Transitoria 26, en cuya virtud se establece un mecanismo transitorio para la elección de los gobernadores regionales y realiza adecuaciones a varios cuerpos legales.

f) Por último, la Ley No 20.990, que crea una Disposición Transitoria 28, en cuya virtud fija reglas para la elección popular del órgano ejecutivo del Gobierno Regional.

A las reformas constitucionales antes señaladas, se deben agregar las leyes de reforma a la ley orgánica constitucional No 19.175 sobre Gobierno y Administración Interior del Estado, como son:

a) La Ley No 21.073, de 22 de febrero de 2018, sobre Elección de Gobernadores Regionales y que adecua y modifica diversos cuerpos legales.

b) Finalmente, se dicta seguidamente una norma del mayor interés, la Ley No 21.074, de 15 de febrero de 2018, sobre Fortalecimiento de la Regionalización del País.

El nuevo Estado regional debe reconocer en la región el motor de desarrollo y un centro de decisiones administrativas que se funde en el principio democrático. Sin duda, constituyen avances importantes la elección directa de los 
consejos regionales por la ciudadanía regional y la inminente aplicación de la elección directa del gobernador regional que preside el gobierno regional, como máxima autoridad administrativa de la región; quedando reservado a los delegados regionales presidenciales y delegados provinciales presidenciales la función de gobierno en la región y provincias, conservando el carácter de agentes naturales y directos del Presidente de la República en el territorio.

Esta profundización de la democracia regional se ha visto limitada por el insuficiente proceso transferencia de competencias que, en absoluto, sugiere la idea de descentralización en los propios términos descritos por la actual Constitución de 1980 en su artículo $3^{\circ}$ y artículo 65, inciso cuarto numeral $2^{\circ}$. Por ello, sostener que el actual régimen de transferencia de competencias es una acción descentralizadora es, por lo menos, desconocer la legalidad de dicha técnica y, en consecuencia, forzar los términos de una realidad inexistente.

En este contexto la única descentralización que ha operado de modo significativo es la creación del órgano gobernador regional y la única experiencia de autonomía política para la población regional es el ejercicio del derecho de sufragio para la elección de las autoridades de naturaleza electiva, debiendo tolerarse la presencia de órganos de la Administración Pública con bajos niveles de legitimidad democrática.

Cabe señalar que Estado regional supone la máxima transferencia de las funciones y potestades administrativas al Gobierno Regional. Es indispensable en Chile consagrar una nueva distribución territorial del poder político, que profundice el proceso de regionalización y que concrete la anhelada descentralización administrativa del país, instaurando un auténtico e inconfundible Estado regional.

Para concretar lo anterior, es indispensable separar las funciones de GobiernoAdministración en la región, quedando el delegado presidencial regional circunscrito, exclusivamente, al campo gubernativo, eliminado la delegación provincial del Gobierno y conferir al gobierno regional un abanico de funciones y potestades administrativas ordenadas al desarrollo y participación regional, resultando de primer orden consagrar la hacienda regional que permita concretar las políticas públicas regional; así como también los principios de solidaridad territorial entre las distintas regiones que se expresen en mecanismos de compensación financiera que aseguren el desarrollo equitativo de todos los habitantes de la república.

Y tratándose del consejo regional un efectivo estado regional debe dar paso a la transformación de éste en una asamblea regional dotada de potestades normativas, resguardando su debida armonización de las políticas y planes nacionales, que admitan un grado de descentralización política compatible con esta forma de Estado.

El Estado regional deberá conferirles encaje a los territorios de pueblos indígenas en conformidad con la ley.

En definitiva, un Estado regional, como una forma intermedia entre el Estado unitario y el Estado federal, supone un máximo de transferencia de potestades administrativas al Gobierno Regional y que aborde la regionalización como un proceso, que posea áreas metropolitanas efectivas y mitigue los efectos de las "mega" regiones.

\section{Conclusiones}

La reforma constitucional de 2017 sumariamente abordada, se produce en el contexto de un empeño del segundo gobierno de Bachelet en orden a instalar una nueva Constitución, empeño malogrado en el cuadrienio (2014-2018). 
Precisamente este empeño es un flanco crítico también: por qué discutir separadamente la forma jurídica de Estado de otros cambios tan sustanciales como el perfeccionamiento de la forma política estatal: la república democrática y de la forma jurídico-política de un Estado social y democrático de derecho.

Sin embargo, este flanco crítico prescinde de la realidad: la descentralización y más democracia a nivel regional no pueden esperar; como esperó el constituyente de 1925 la creación de las "asambleas provinciales". La larga espera en materia de forma jurídica del Estado, que supone el centralismo, es fruto del anotado "peso del pasado", que se proyecta en la teoría constitucional como un verdadero paradigma conceptual que García Pelayo (1950/1984: 41-45) explicitó en el esquema trinitario: Constitución racional normativa, Constitución sociológica y Constitución histórica-tradicional. El concepto histórico tradicional es conservador (o reaccionario): mira al pasado como si fuese un "orden inmutable" y de allí su conexión ideológica con el historicismo; se resiste a la idea de un plan racional propio del liberalismo del siglo XVIII y XIX o del socialismo del siglo XX. En este orden, el Estado unitario es postulado como la única forma de organización territorial del poder, dado que el pasado institucional la valida como la única posible o deseable; es parte de la Constitución histórica y de la Constitución material.

La amarga lección para el sistema democrático como es la decreciente participación política del pueblo en los procesos electorales es demostrativo de ello. La suerte de "fatiga o desinterés electoral" que hoy nos aqueja se corrige (más allá del debate acerca de la obligatoriedad del derecho de sufragio) abriendo las instituciones a la participación del pueblo y restableciendo el sufragio universal obligatorio; expresión cabal de la "sala de máquinas" (Gargarella, 2014) del Estado.

De esta manera, conecta el nuevo reparto del poder político en el territorio de un Estado regional con el sistema de derechos. Se materializa el deber o mandato dirigido a los órganos del Estado en orden a respetar, promover y asegurar, en todos sus niveles de protección, el pleno ejercicio de los derechos humanos, propendiendo a su progresividad, expansividad y óptima realización posible, lo que unido a la descentralización permitirá mayor igualdad y mejores oportunidades para las regiones.

Asimismo, un Estado "democrático" debe asegurar también los derechos políticos: sufragio universal, asociación política, protección del Estado a los nacionales, nacionalidad, el derecho a una buena administración, el derecho de acceso a los documentos, el derecho de petición a la autoridad y el derecho de reunión y manifestación; el derecho a la participación política y social, como garantía del orden político e institucional y como derecho incluyente de los grupos históricamente excluidos de los espacios de toma de decisiones públicas.

Ahora bien, una y otra definición (que el Estado sea tanto social como democrático) no significan mucho si la vigencia efectiva de los derechos y las oportunidades para participar tanto de la vida política como económica de la nación están determinadas por el lugar en que una persona nazca o resida. Por eso, la nueva Constitución debe reconocer el derecho de todos los habitantes de la república a tener oportunidades equivalentes de participar en las decisiones democráticas locales, regionales y nacionales y, a la vez, de beneficiarse del desarrollo económico.

Para que esa última definición sea efectiva, el diseño institucional que se haga a nivel local, regional y nacional en la nueva Constitución debe contemplar los equilibrios adecuados, que permitan la capacidad del Estado nacional para cumplir con sus funciones propias, pero que también asegure una eficiente y eficaz actividad pública de municipalidades y gobiernos regionales. 
En ese sentido, la agenda de descentralización del segundo gobierno de Bachelet ha avanzado; y hoy se evalúan de manera positiva las nuevas reglas que dispone la Ley No 20.990 consistente en la creación del órgano del gobernador regional como autoridad electa.

Lo anterior no excluye la revisión del reparto territorial del poder político estatal en el marco de una nueva Constitución, de suerte de acoplar correctamente las piezas de la máquina estatal; es decir las decisiones fundamentales (bases de la institucionalidad) relativas al Estado, la economía, la sociedad y las personas con el arreglo institucional que Chile finalmente asuma.

Tampoco excluye lo dicho en el debate acerca de la "provincialización" del proceso de regionalización; que parece dar cuenta de una realidad identitaria en lo territorial, político, económico y cultural de raíz histórica. Es el peso de las 25 provincias que Chile tenía y que se remonta a las ocho provincias de los orígenes de la república. La "provincialización" nos obligará a debatir acerca de "macro-regiones"; que conjure un nuevo-viejo riesgo para el Estado regional como es la "mega-región" (Boiser, 2004).

Por último, un Estado regional en el debate de nueva Constitución debería hacerse cargo de una distribución territorial del poder, en sus funciones políticas y administrativas; eliminando o racionalizando la supervivencia de los "prefectos" (delegados presidenciales regionales y provinciales), e instalando en el gobierno regional una "Asamblea Regional" con potestad legislativa, y reforzando a través de este órgano el control político del gobierno regional.

Finalmente, en el marco de la nueva Constitución se debe abordar primero el encaje de territorios indígenas en las regiones del país, y la composición de conflictos o "cuestiones de competencia" que pudieran suscitarse entre autoridades nacionales, regionales, provinciales y comunales; que pudiera reforzar la competencia de "tribunal de conflictos" de un nuevo Tribunal o Corte Constitucional.

\section{Bibliografía}

Boiser, S. (2004). Desarrollo territorial y descentralización. El desarrollo en el lugar y en las manos de la gente. Revista Eure, 90, 27-40.

Chapman, B. (1959). Los prefectos y la Francia provincial. Madrid: Instituto de Estudios Políticos.

García Pelayo, M. (1950/1984). Derecho Constitucional Comparado. Madrid: Alianza Editorial.

Gargarella, R. (2004). La sala de máquinas de la Constitución: dos siglos de constitucionalismo en América Latina (1810-2010). Buenos Aires: Katz editores.

Heise González, J. (1954). Historia Constitucional de Chile. Santiago: Editorial Jurídica de Chile.

Heise González, J. (1960). 150 años de evolución institucional. Santiago: Editorial Andrés Bello.

Luksic, Z. (1992). Algunos contenidos fundamentales de la descentralización regional y municipal: el concepto de autonomía, el orden económico de la descentralización y una visión gradual del proceso. Cuadernos de análisis jurídico, 20, 35-48.

Marx, K. (1842-1843/1983). En Defensa de la Libertad. Los artículos de la Gaceta Renana 1842-1843. Valencia: Fernando Torres Editor.

Mortati, C. (1940/2001). La Constitución en sentido material. Madrid: Centro de Estudios Políticos y Constitucionales.

Véliz, C. (1984). La tradición centralista en América Latina. Barcelona: Ariel. 
Zúñiga Urbina, F y Peroti Díaz, F. (coords.). (2020). Bases y fundamentos de una propuesta constitucional progresista. Disponible en: https:// institutoigualdad.cl/2020/11/26/

bases-y-fundamentos-de-una-propuesta-constitucional-progresista/ 